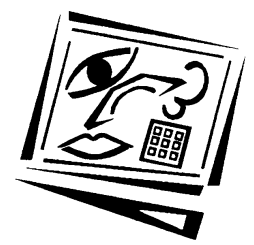

\title{
Finding the discipline: Assessing student activity in Second Life
}

\author{
Scott Grant and Rosemary Clerehan \\ Monash University, Australia
}

\begin{abstract}
For the second-language learner, the affordances of a virtual world have the potential to confer benefits conventionally aligned with real world experiences. However, little is known about the pedagogical benefits linked to the specific characteristics of the virtual world, let alone the issues arising for staff hoping to assess students' participation in these worlds. This case study is based on a two-part assignment in a first-year Chinese unit at an Australian university, exploring the virtual world assessment practices of one lecturer. The findings, while suggesting the strengths of the assessment regime with respect to many of the affordances and to alignment with policy, highlight deficient aspects of the design and implementation processes which can relatively easily be addressed. The case study reveals the critical importance of sufficient scaffolding and support, feedback and appropriate communication of students' achievement to them in order to promote further reflection.
\end{abstract}

\section{Virtual worlds and second language learning}

Substantial amounts of time and resources are devoted by institutions to the construction and maintenance of virtual worlds such as Second Life, but surprisingly little is known about the pedagogical benefits linked to the specific characteristics of the virtual world, let alone the issues arising for staff hoping to assess students' participation in these worlds. Dalgarno and Lee (2010), in their comprehensive roadmap for further research, emphasise the importance of evaluation to determine whether such outcomes as improved contextualisation of learning and more collaborative learning exist; and whether tasks meet desired educational outcomes (Chen, 2010, p. 25). Rich accounts of innovative uses of virtual worlds in higher education are still lacking (Deutschmann, Panichi \& Molka-Danielsen, 2009). By exploring the assessment practices of one lecturer in a case study, we hope to contribute to this literature.

Web-based online environments in higher education have largely been disembodied experiences. This is in the face of contemporary educational theory which emphasises the significance of maximising embodied contextual experience to stimulate learning and fully engage learners (Migdalek, 2002). In a virtual world, gesture and actions can be aligned with words (Cheng, Farnham \& Stone, 2002). This affordance for the second language learner has the potential therefore to contribute pedagogical benefits conventionally aligned with real world experiences, arguably constituting an advance on the standard classroom language drills ('pretend you're at a dinner party in Florence'). 
A virtual world can be a linguistically apt environment which fosters pedagogically appropriate behaviour, including synchronous interactions. It is a 3-D graphical space for which there can be game-like elements, but there are no pre-set rules and objectives; although these can be set by users (lecturer or learners) (Henderson, Huang, Grant \& Henderson, 2009). In any case, as Meyer (2009, p. 715) points out, 'games and simulations have been part of language learning for decades', and they also have the capacity to be fine-tuned for both formative and summative assessments (Hudson \& Bristow, 2006). Next we make brief comment on the value of virtual worlds for language learning and introduce the case study. Literature relevant to the pedagogical design and assessment is considered later in the paper.

Factors identified as important for language acquisition are exposure to linguistic (and non-linguistic) input; opportunities to produce linguistic (and non-linguistic) output; and opportunities for meaningful communicative interaction and corrective feedback (Ellis, 2008). Particularly with respect to communication practice, virtual worlds provide a complementary environment and opportunity in which communicative tasks can be contextualised and made more meaningful. This is achieved through careful design of the environment to include physical aspects and activities closely aligned with real life and careful task design based on sound pedagogy. An additional pedagogical affordance for the study of Chinese language is the ability to utilise textbased synchronous computer mediated communication to strengthen learner mastery of Hanyu Pinyin (the spelling of Chinese characters using the alphabet) and character recognition, through dynamic communicative interaction with peers, instructors and programmed agents (non-player characters) within the environment. This in turn has additional benefits in terms of strengthening oral acquisition through what Beauvois (1997) calls 'conversation in slow motion'. While many affordances of virtual worlds have been identified as conducive to language learning (Chen, 2010), there has been little published research on the issues surrounding assessment of such innovative practices.

The data from this case study will be discussed within a framework devised for an Australian Learning and Teaching Council (ALTC) project, 'Web 2.0 authoring tools in higher education learning and teaching: New directions for assessment and academic integrity'. This project aimed in part to establish industry-wide guidelines for the design and implementation of valid assessment models for Web 2.0-based learning by exploring a number of case studies. Web 2.0 is defined by Harris and Rea $(2009$, p. 137) as 'a perceived second generation of Web development and design that facilitates communications and secures information sharing, interoperability, and collaboration on the World Wide Web'. They include virtual worlds in a list of more conventional Web 2.0 applications such as wikis, blogs, podcasts, and social networks. Some have even hailed virtual worlds as Web 3.0 (Smart, 2010). Following Elliott's (2008) criteria, the principal aspects of Web 2.0 learning which are most relevant to virtual worlds, in addition to the open-source software employed, are user-directed content and use of collective and collaborative intelligence. Elliott has been one of the first to attempt to formally conceptualise assessment in relation to Web 2.0 (referred to by Elliott as 'Assessment 2.0'), listing 10 criteria which serve as a useful starting point (Elliott, 2008, p.5). As indicated below, the assessment adopted for the case study meets a number of Elliott's criteria.

In the present paper, data are presented and discussed under the conceptual framework of Affordances, Processes and Policies, which are categories derived from our reading of the literature on student Web 2.0 activities and used to guide the interviews 
with lecturers (Gray, Waycott, Clerehan, Hamilton, Sheard \& Thompson, 2010). Under Affordances (see also Waycott, Gray, Clerehan, Hamilton, Richardson, Sheard \& Thompson, 2010), we include the capacity of the virtual world to promote open publishing; encourage different communication styles; expand students' sense of their personal identity and experience; promote co-creation and collaboration; and enable student control of content. Processes include the design of the assignment, the implementation, marking, feedback and reviewing and monitoring. Policy questions concern equity of assessment; access to IT services and equipment; identity and privacy; and academic honesty and integrity. In the final two sections, issues arising from the case study are discussed and interpreted.

For the ALTC project, focus groups were conducted with 20 students from the different courses whose lecturers had participated in the project. The current case study will include comments from the four students who were enrolled in the Chinese 1 unit.

\section{The case study}

The paper presents a detailed exploratory case study of a lecturer's (the first author's) assessment of students' use of a virtual world, using the lecturer's and students' perspectives of the assessment as units of analysis (Yin, 2003). To this end, we deployed a combination of lecturer narrative, subject artefacts, case study notes (including class observations) of both authors, and student focus group data. The second author interviewed the lecturer several times over a semester, taking notes and checking them, when written out in full, with the lecturer, using the terms of the framework to guide the discussion. The second author also observed student activities in laboratory sessions. The student focus groups were conducted as part of the ALTC project by the Project Officer, using the framework. Ethics permission was granted from the university involved, and focus group participants were assured their responses would be anonymous. Transcripts were analysed in light of the framework. It should be noted that the focus groups were conducted at the end of semester and students' memories of the lesson and of the assessment may have faded somewhat.

The subject was Chinese 1, a first year unit in a Bachelor of Arts at a large urban campus of an Australian university. It was compulsory for some students and elective for the rest. The unit provides an introduction to spoken and written modern standard Chinese to students with no prior knowledge of Mandarin. About 140 students were enrolled in 2010, of whom approximately 70\% were local students whose main language was English, but some of whom also spoke another language at home; and $30 \%$ international, with Asian and other language backgrounds. The lecturer and two (Chinese national) sessional tutors took the three 1.5-hour laboratory classes. This assignment was initiated only in 2008, and 2010 was the first time the virtual world assignment was formally assessed.

For the assignment students were required to go to a virtual Chinese restaurant on the university's Chinese Island in Second Life, as seen in Figure 1. In the first part of an assignment worth $10 \%$ of the total marks for the unit, students were required to identify and order specific dishes in Chinese; in the second, to find out how to purchase certain ingredients and ultimately to cook a dish using the ingredients (see Appendix for desired learning outcomes). 


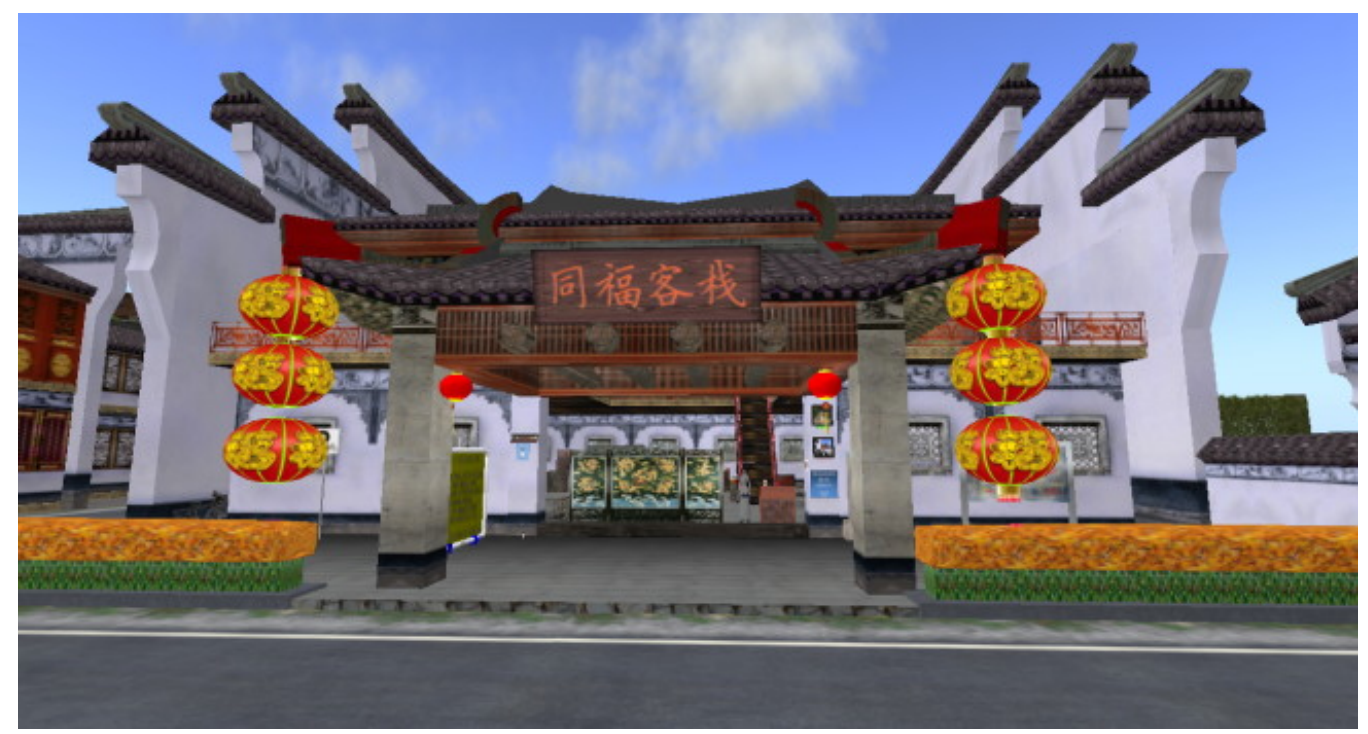

Figure 1: The restaurant on Chinese Island

Students initially participated in a lesson designed to allow them to learn and practise basic Second Life technical skills. This also familiarised them with the environment to reduce the impact the technology would have on engaging with the disciplinary content, an issue highlighted by Chen (2010) in a study on the experiences of 26 Chinese language students who undertook compulsory lessons in Second Life. Students also watched two videos on inputting Chinese characters and were encouraged to complete online exercises to practise typing. Refresher information on these basic skills was also subsequently provided in the Lesson Manual for the second lesson, which also included additional background cultural information (textual and pictorial), new word lists and suggested expression lists for conversation with the non-player characters.

The content of the lessons and assessment was based on linguistic and non-linguistic knowledge previously learned in other parts of the classroom-based curriculum (from lectures, seminars, tutorials and the main textbook) and guidance and scaffolding of students in relation to disciplinary content during the lesson was set with this prior knowledge in mind (Kirshner, Sweller \& Clark, 2006).

\section{Assignment - Part 1}

The task

For the first part, in Week 8, students had to form groups of four and each member was given a role to play with specific dietary needs (a vegetarian, a diabetic, a Muslim, a person who could not eat spicy food). Once seated in the virtual restaurant, each member of each group had to tell the other group members in Chinese their dietary needs. Based on this, each member had to guess which role the others were playing. Each group then had to collect information about the ingredients of a range of dishes commonly found in mainland China (17 in all), discuss what they had found, and decide which were appropriate for each of the specific dietary needs. Finally each group was required to order in Chinese the dishes they had decided on while teaching 
staff, in the role of waitresses, went around inworld (i.e. within the virtual environment itself) to each group and asked for their order.

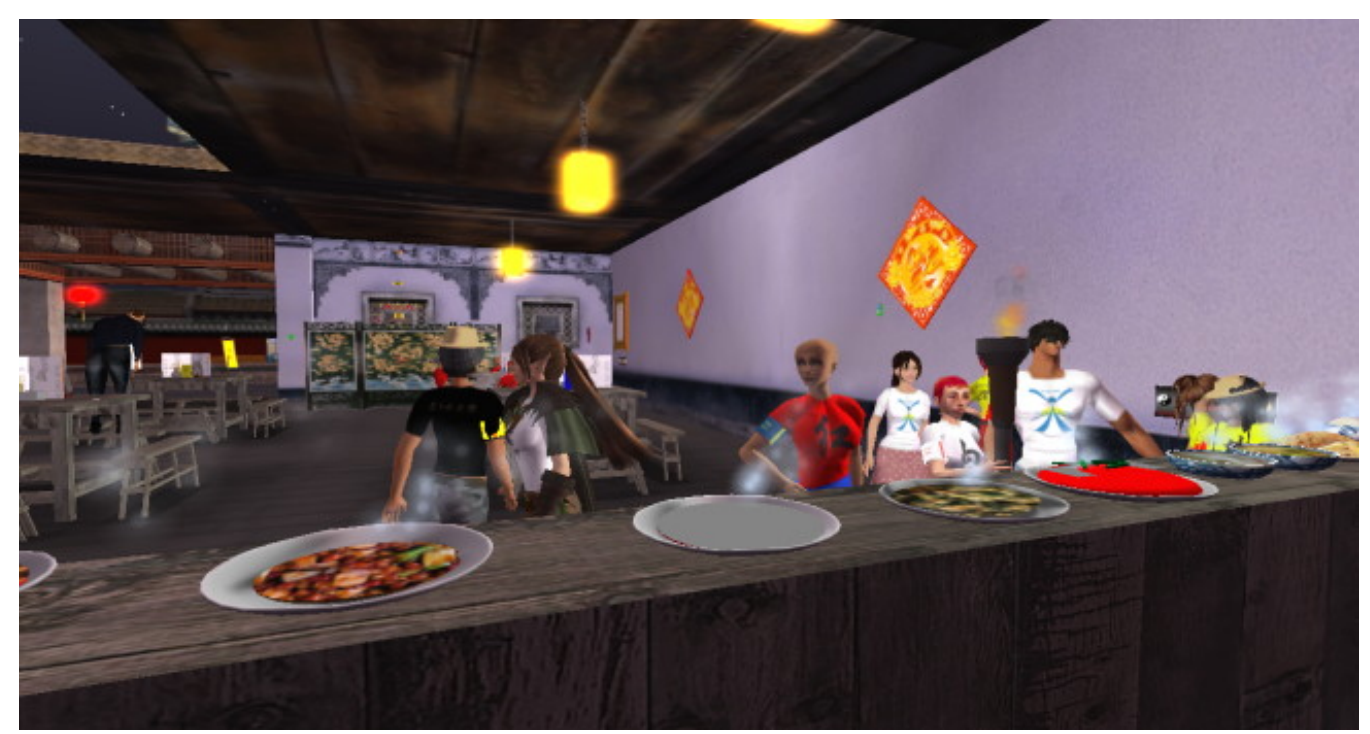

Figure 2: Ordering dishes in the restaurant

The assessment

Formal assessment was divided into two parts: group assessment and individual assessment. Group assessment was based on a visual inspection by teaching staff inworld of the dishes ordered (a number of different combinations were all correct), and group marks were allocated and recorded by staff in the real world based on the number of appropriate dishes ordered. The vocabulary and phrases used in the lesson to order food were drawn from the textbook, a key aim of the lesson being to consolidate student knowledge of, and ability to use, this language. Students therefore had to produce conversational language in Chinese to be able to complete set tasks.

Individual assessment was to be based on a quiz on Moodle that was designed to provide a summative assessment of individual student learning performance. The quiz was based on the descriptions in Chinese of the dietary needs each student gave to the others in their group and on the names and prices of the dishes ordered. Half the marks available were to be allocated to correct dish choice and half to the quiz. Unfortunately, due to students taking longer than expected to complete the set tasks, only a third of them were able to attempt this assessment. This is further discussed in the section 'Assessment Issues'.

\section{Assignment - Part 2}

The task

For the second part, in Week 12, students were expected to complete a task involving buying a bowl of soup dumplings for a hypothetical teacher. In order to do this they had to find a friend of the teacher in the restaurant who had information needed to complete the task. The role of the friend was played by an automated non-player character. To locate and identify the friend students had to engage in typed 
conversation with both the friend and another restaurant employee, also a non-player character. Students then had to purchase a particular ingredient for the dumplings in a virtual farmers' market, where they went following directions provided by the nonplayer characters in the restaurant. They then had to purchase the ingredient by engaging in dialogue with another non-player character in the market (a fruit and vegetable seller). In the final stage, students were required to return to the restaurant and, following instructions given to them by one of the non-player characters, go into the kitchen and 'cook' a bowl of dumplings using the ingredient.

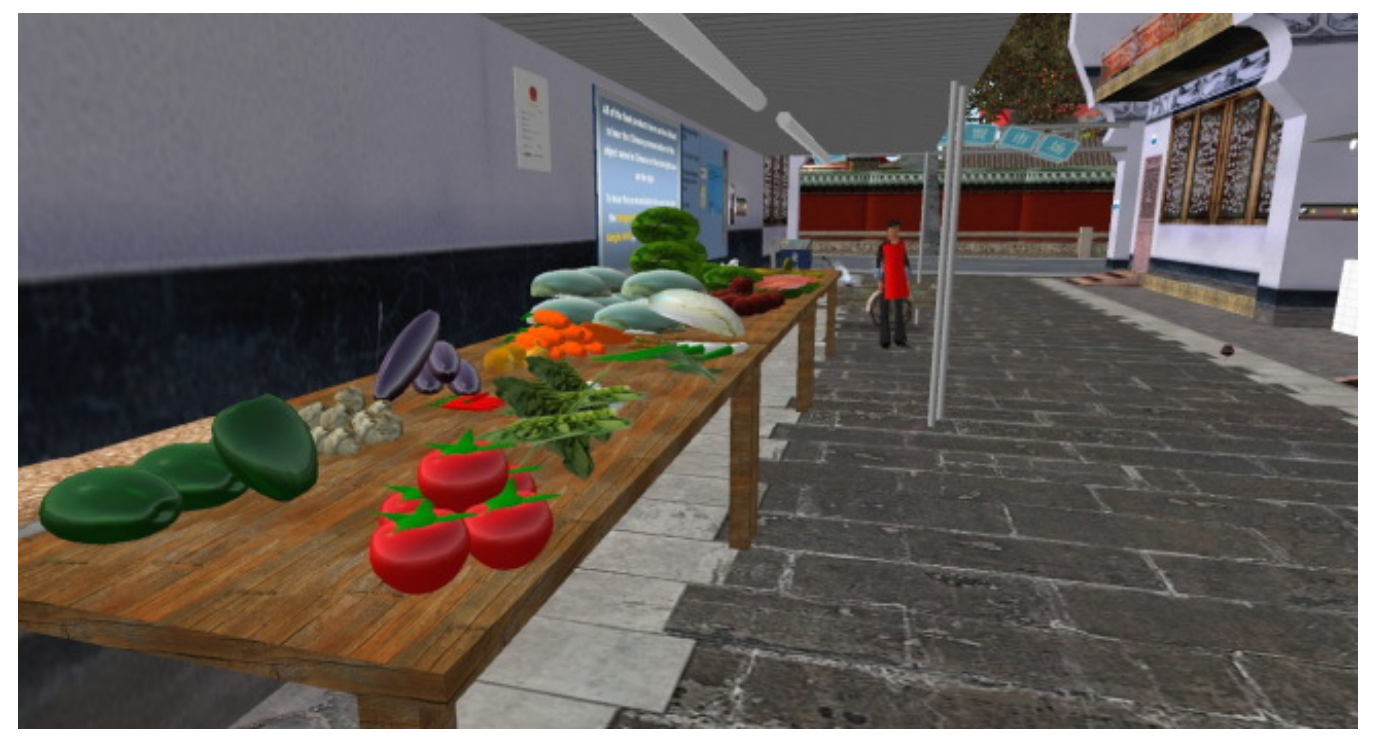

Figure 3: Ingredients at the market

The assessment

Formal assessment in the second part of the assignment was conducted on an individual basis only. Prior to the lesson, students were given a rubric outlining how they would be assessed. The rubric was as follows:

5\% Completed task, dumplings shown to teacher (must show dumplings to Monash teacher in Second Life).

4\% Did not complete task, but successfully purchased necessary item for completion of task (must show item to Monash teacher in Second Life).

3\% Did not complete task, did not successfully purchase necessary item, but found location where item is sold (must show instructions for getting to location to Monash teacher in Second Life).

1\% Did not complete task, did not purchase necessary item, did not find location where item is sold, did find Teacher Zhang's friend (must show dialogue where friend confirms they know Teacher Zhang to Monash teacher in Second Life).

At the end of the allotted time, teaching staff went around to each student's computer terminal and checked on what stage they had reached. Marks were allocated on the spot. 
In the next section, we elaborate on the underlying pedagogical design of the whole assignment and its assessment.

\section{Pedagogical design and desired learning outcomes}

The rationale for using the virtual world was to provide an experience which could prime students for similar experiences in a Chinese environment in the real world, while consolidating and extending formal classroom/textbook based learning and knowledge (see Appendix). The deliberate inclusion of a number of 'information gaps' meant that students had to think their way through to the next move, based on the question: 'What would you do in real life?'

From the perspective of second language acquisition theory, Second Life was seen as an environment that could provide opportunities for students to be exposed to meaningful comprehensible linguistic and cultural input and to produce comprehensible output, both important for second language acquisition (Swain, 1995; Ellis, 2008; Foster \& Ohta, 2005). Interaction in the environment was intended to be more 'authentic' than in the classroom in that it was part of larger meaningful tasks that were relevant to, and simulate, the real world. The lessons were also designed to foster the use of linguistic and cultural skills and knowledge in a purposeful way, not just 'practising for the sake of practice' (Diehl \& Prins, 2011). From a pedagogical perspective, the lessons were designed to develop communicative competence, selfefficacy and cultural knowledge. This was to be achieved using knowledge and skills derived from learning in the formal classroom; from ambient and targeted information within the virtual environment; and through interacting with teaching staff, peer team members and artefacts (including non-player characters) in both the virtual and real world environment to problem solve and complete set tasks.

The lessons were also designed to facilitate collaborative learning and peer scaffolding (McLoughlin \& Lee, 2007). That is, students could work and problem solve in groups or pairs within the virtual world and in the real world, either formally (required as a part of the lesson) or informally, as they encountered various barriers to the completion of the set tasks. In the second part of the assignment the non-player characters, who could engage in multiple conversations simultaneously, were key interlocutors and providers of task-related information. This allowed students to get on with tasks at their own pace, leaving teaching staff free to provide greater one to one scaffolding as they assisted students both in the virtual environment and in the laboratory.

Interesting questions are raised by the assignment about the relationship between formative and summative assessment. For our purposes, formative crucially involves feedback to improve student learning, and summative provides a judgment about student performance at a particular time. Taras (2008, p.173) notes that the education community has, by and large, not prioritised 'the harmonisation of the two processes' so they can be 'mutually supportive' (p. 189), and reports that students (and possibly lecturers) are not clear about the distinctions between the two. The two parts of this assignment demonstrate a way in which the two are can be interwoven in the very conduct of a task. Formative assessment is afforded by the continuous feedback from non-player characters, teachers and peers, providing ongoing input which students take into account in order to move on. Summative assessment is represented by the quiz in lesson one and via the rubric for lesson two. 


\section{Exploring the project framework}

In order to explore how the elements of the case study played out with respect to its assessment, the framework, encompassing Affordances, Processes and Policies, is used to structure the following section. The section includes comment from the four students who participated in the focus groups

\section{Affordances}

The Second Life, do you guys know what that is? It's like you have this little person that walks around in this 3D virtual world thing. And we had to do a lot of assessment, we had to do some assessment for it in Chinese, so you know how you can type in and the characters will come up? You had to go around and ask the woman something about dumplings and then she said, OK I don't have any dumplings, go get me the cabbage and I'll make you dumplings and then you have to go somewhere else and follow directions in Chinese and go talk to the market guy in Chinese or whatever to get your cabbage (Student 9 (S9)).

Affordances as potentials for action may be translated in the educational context to the dynamic relationship between the technology and the student, which enables certain kinds of learning to occur (McLoughlin \& Lee, 2011). While acknowledging this dynamism, the relationship will be disaggregated for the purposes of analysis into the technical features and the perception of the students, as exemplified in the quote above.

The 3D virtual environment afforded spatial qualities which allow the practice of activities such as taking and giving directions to be facilitated in a rich and realistic way, an affordance which has also been highlighted by O'Brien and Levy (2008) and Cheung, Zhan and Tsai (2010). Communication in these environments is 'multichannelled' in that it can occur via voice communication and public and private textbased communication simultaneously. When working in groups for this assignment, students could move off to another area within the virtual space so as not to interfere with other groups, and could also easily hold private conversations.

For the two tasks, the outcome of student efforts to complete the set task could be seen by them as well as by teaching staff. Key information was provided in text-based form within Second Life and in conversations with non-player characters. In the case of the first part of the assignment, information about the dishes was stored in the form of note cards that could be accessed by clicking on each dish, and in the second part key information was obtained by students engaging in text-based conversations with the relevant non-player characters.

From the technical perspective, inworld interaction and collaboration occurred, then, in two modes. The first was the visual, with all participants able to see what others were doing and what stage of a task they were at. The second was text-based dialogue (in English and Chinese). Particularly during the first lesson, students communicated via 'group IMs' (instant messages) in the form of text-based discussion, visible to all members of a particular group and also to teaching staff.

The complex opportunities presented by such affordances were reported by focus group students as challenging. While students had been encouraged to complete the online typing skills exercises prior to the class, less than half did this. Student 11 
commented that he expected microphones but it was 'just text'. Student 10 found the task 'pretty complicated', especially with the typing of Chinese characters (which was still, he thought, 'good practice'). Collaboration was regarded by him as 'a bit difficult': 'something that will take me 30 seconds in real life will take me five to ten minutes in the virtual world'.

Further affordances seen as characteristic of Web 2.0 and generally regarded as positive for assessment of student learning were available in this assignment. Open publishing allows work to be available for others to see, and for students' sense of their personal identity and experience to be expanded (Gray, Thompson, Sheard, Clerehan \& Hamilton, 2010). From the focus group students' perception, however, for this assignment, the first of these affordances was seen as in conflict with the second. Because individuals were not recognisable from their avatars, it was not clear who people were: 'It's really strange, because then the person that you're talking to might not even be female ...', and 'Most people had weird names, like one had Fifi the Cat' (S1). He said he was fortunate that he had a friend doing it with him to whom he could talk in the lab; Student 9 reported it was very difficult to work in a group 'where you can't actually see the person'. Student 1 also conceded, however, that there were learning benefits afforded by the expansion of experience:

It was all like direct speech which was good because that's what real life was like. So you had to use sentences apart from, my name is such-and-such and I study Chinese. It was more like, how do I get to this place? What do I have to do?

Student control of content is another affordance often nominated as a benefit of Web 2.0 (McLoughlin \& Lee, 2007). In this virtual world case, 'student work' was only 'accessible' for the duration of the lesson. It would be possible to make the text-based and visual representations of student work available to all students via posting on a website; and, as a follow up step, this could enable students to post a reflection on their experience, fostering further ownership of it.

\section{Processes}

The assessment processes as identified in the project framework (Gray, Waycott, Clerehan, Hamilton, Sheard \& Thompson, 2010) included the design of the assignment, the implementation, marking, feedback and reviewing and monitoring. In this case, all students and staff were pre-issued with lesson goals, tasks and assessment guidelines, as outlined previously.

The first lesson was designed to promote group collaboration and three kinds of informal mentoring. First, mentoring with technical skills, as some students were more experienced with virtual worlds and some were more experienced with skills required to input Chinese characters. Second, mentoring with regard to task requirements as some students grasped requirements better, and third, mentoring in relation to language knowledge. Student 9 believed that the design of the assignment 'was so intricate some people just couldn't handle it', but acknowledged that it provided learning possibilities not available through traditional means:

It gave something different and it gave a context to it, [... ] in that you had to kind of think on your feet for it, it wasn't something you could prepare too much for and it actually had a point, you were actually going somewhere for it. 
Recalling it quite well, she further commented that the assessment was 'weird' - if you got the dumplings, you got $5 / 5$, but if you got the cabbage, you'd only get $3 / 5$ !' (whereupon, incidentally, a focus group student from a different unit exclaimed: 'It sounds so good!').

The assessment was so embedded in the task that some students were unaware of its happening. Student 10 reported that he 'didn't like' how the assignment was assessed because the program was 'very difficult to use' and further, thought 'we didn't see the results for the Second Life'. Similarly, Student 11 could not recall being assessed: 'we didn't know, we didn't get feedback, we didn't - because usually there was like a test or something, to see if you could complete the task but I never knew my grades'. Student 9 told the group she felt that it would have been 'far better as a learning tool'.

In the second lesson, the dumpling scenario, the 'content creation' used as assessment milestones (finding the teacher's friend, finding the vegetable market, and so on) was done on an individual basis. Students were encouraged to work in pairs to provide mutual support: interaction around the monitors was also actively encouraged, with learners actively seeking help from peers who would often walk around the computer island to look at the screen of the person they were helping. Student 1, while describing the assignment as 'awesome', felt the process was 'a bit chaotic: everybody sort of doing things at once - it was hard to control', to the point where she claimed, of Part 2:

No idea how it was assessed, if it was assessed, and if so like is there a grade? If there is I don't know what it is. If I have been graded on this, it's really unclear to see how, because I don't understand how they could grade it.

The lecturer considered that the students received three main kinds of feedback. First, when interacting with the automated non-player characters, the non-player character often asked for the utterance to be repeated, which led to a correction of form or lexis and the conversation moved on. Sometimes, due to the inputting of incorrect characters or terms, the conversation was unable to move on and the student became 'stuck'. Student 9 commented:

it took a lot of time to teach people how to actually use it and then how to type in characters and then some of the simulated ones you'd ask it something and it wouldn't quite get what you were on about even though it should have.

This often led to the teacher being called for help. At this point, the student received individualised feedback to isolate the problem and work on a solution. The third kind of feedback, as indicated above, came from peers, generally when assistance was sought by a student unable to obtain information they required from conversation with a non-player character. Throughout both sessions the lab was observed to be abuzz with activity, with students constantly talking to each other or to themselves.

Managing the kind of assessment that was done involved exhausting work for staff (although correcting 144 standard written tests can be similarly taxing). However, as the lessons appeared more like formative assessment and students would have learned additional material that was not specifically assessed (Diehl \& Prins, 2011), staff viewed extra effort as worth it. Internal review took place with the other tutors and the visibility of the student activity provided the lecturer with ample information for assessment review, but learning outcomes may have been achieved in ways that were hard to measure. 


\section{Policies}

Several issues arose to highlight the policy questions of equity of assessment; access to IT services and equipment; identity and privacy; intellectual property; and academic honesty and integrity. The first equity issue arose as some students pointed out to the lecturer that the assignment was not equitable because some groups did not get to the point of dishes on table. The lecturer, however, was able to go back to the logged dialogue to see what they were planning to order and explained that he could ensure there would be equity as the log could be checked.

One focus group student pointed out that there were so many students and only a few staff, 'they can't help everyone at once' (S11). Another felt that students who didn't have 'someone who was helpful and good at it sitting next to them' would feel disadvantaged (S9) - which could be regarded as a hazard, difficult to manage, of any assessable group work. Indeed, everyone was able to access the same equipment and resources. Interestingly, one student could not be physically present during the second lesson and completed it in Second Life from her interstate location, using photographs (screen grabs) as evidence of her having completed various stages of assessment. Another student (S11), however, commented that that wouldn't be possible for him due to the slowness of the home Internet.

From the student focus groups the concern for privacy seemed to vary according to the degree of exposure of each Web 2.0 environment. One student's avatar accidentally ended up 'bald in a string bikini' and he did not appear to be fazed by this; Student 10 'commented, 'personally, I think it was all fair - you had your identity protected'.

The making of objects can raise an issue of intellectual property rights in some Second Life programs. Some consideration was given during the second lesson design process to make photographs taken by students a part of the assessment (for example, photographs identifying foods that students were asked to locate); however it was decided that, to prevent any intellectual property issues, they would not be required to take and transmit photographs. So, the content for the lessons concerned was only 'public' for a limited period of time and the resulting 'content', that is the food ordered or the dish made in the kitchen, was removed after being noted.

The only other policy issue which arose concerned the fact that students were also encouraged to refer to their textbooks during the lesson and a couple of the focus group students thought that was 'like cheating' (S1 and S9). Further, student 9 commented that, at the market, 'you could see everyone else and just follow them', so you could do that without attending to the directions, which felt like bending the rules.

The following sections discuss the assessment issues arising from the case study.

\section{Assessment issues}

One of the key issues arising from the assessment of students' Web 2.0 activities is the prospect of how lecturers develop genuinely Web 2.0-responsive assessments. Reports in the literature, by and large, are not revealing widespread attempts to do more than traditional types of summative assessment, and in fact formative assessment is typical (Dalgarno, Lee, Carlson, Gregory \& Tynan, 2011). The current Second Life assignment 
was new and innovative, used formative and summative assessment, and is therefore hard to measure against obvious benchmarks.

With a large proportion of the group from different backgrounds, there may have been a mix of student perspectives, not all of which could be captured from our focus group data. It should be further noted that the model of learning (from their educational experience) held by some may have been that of individual knowledge acquisition, rather than of participatory knowledge construction.

In the first session the lecturer felt that, although the students received ongoing feedback from the teaching staff and artefacts and agents within the environment, they did not receive particularly useful formal feedback. So, the emphasis of the assessment became more summative than expected, as not all groups were able to get to the point of ordering dishes and marks were finalised only after analysis of the log.

While the assessment in each lesson based on visual sighting of items was a little time consuming for staff, it was able to be completed on the spot for the second lesson. In later lessons a new method was implemented for registering items successfully obtained and students were able to 'submit' items inworld. The items were automatically registered on a database on Moodle which enabled staff to finalise assessment after classes finished, using the permanent record.

Although many students did not have time to do the online quiz, quizzes done in subsequent lessons during the year demonstrated that, once set up, they were relative easy to implement and offered students immediate summative (and in some cases formative) feedback. One benefit of such quizzes in comparison with group work is that quizzes are based on individual performance and provide each individual with feedback on their own - as against the group's - performance. This may be described as something of a hybrid of old and new: using a traditional form of assessment, but providing possibilities for instantaneous summative and formative feedback easily facilitated by Web 2.0 technology.

It would be relatively easy, in our view, to characterise the assignment in terms of traditional principles such as validity and reliability. For example, the quiz in Part 1 could be considered to have high validity in terms of assessing individual students' grasp of Hanyu Pinyin and character recognition (it measures what it is intended to measure); and it could also be said to have high reliability in that it can be consistently scored. In 'Assessment 2.0' terms, however, the authenticity of the task and its potential as a rehearsal for future real world encounters; the student engagement and collaborative work; the problem-orientation; and the capacity to build on existing skills are of greater interest to practitioners seeking to capture the dynamic qualities of Web 2.0 environments in their assessments.

In the future, the first assessed assignment will be re-designed to ensure that students are able to complete all of the set tasks in the time - of interest to other practitioners considering a similar initiative. This will include better training students in basic Second Life skills, making the demonstration of some skills a part of the lesson assessment. Secondly, the number and/or complexity of activities will be modified to ensure that they match better students' level of linguistic and Second Life competence. Thirdly, a new balance between linguistic and cultural content will be struck to reduce the load for students typing Chinese characters at this early stage of study. 
Consideration will be also given to moving assessment from this early lesson to a later lesson when students have higher levels of knowledge and competence, and a better grasp of Second Life skills.

So, areas for improvement are related more to the processes than to the affordances, with some policy implications flowing on from the changes, such as greater equity for all. The lecturer felt that the assessment methods adopted (albeit incompletely implemented) were appropriate and should be easily fine-tuned once the abovementioned adjustments are made. Consideration is being given to the use of other assessment tools that have been integrated with Second Life, such as the Sloodle toolset (a Second Life and Moodle mashup). Greater use of logs for the analysis and assessment of student output and performance will also be considered.

\section{Final reflection}

In terms of the real world application, that is students' capacity to use their personal resources and act as if in the real world, the lecturer was keen to lay emphasis on the dispositions of the students and their ability to interact. The focus group students, on the other hand, were very cognisant of their lack of knowledge, and of not feeling in the position to draw on their own experience and social skills. Researchers and practitioners might take note that the complexity of the task may well have impacted on students' ability to undertake and complete the assessment. The successful practice of what students had previously learned in their course, the teacher saw as equally dependent on their having the knowledge and ability to make the necessary connections. The students, on the other hand, expected more explicit directions from the teacher, rather than being left to 'problem solve' solutions for themselves, and seemed to view inworld assessment as less 'legitimate', especially for Part 2, as the form of assessment was different from the modes they were used to. It is also worth noting that these lessons were embedded in a more traditional curriculum where the 'knowledge' to be learned and assessed was set out explicitly.

There may have been, therefore, mismatches related to different conceptions of pedagogy and curriculum, and thus of the purposes of the assessment. These clashes could in future be addressed by establishing at the commencement a visual matrix for the students, setting out: formative and summative assessments, categorising them as inworld or not; naming the specific areas being evaluated, and available grades; describing the desirable types and degrees of appropriate collaboration; and detailing how each result would be communicated to them. A final reflective online exercise would involve students exploring what, specific to the affordances, they had learned.

The framework of Affordances, Processes and Policies enables us to view this virtual world case study as demonstrating innovation in its interweaving of formative and summative assessment. The findings from the study, while suggesting the strengths of the assessment regime with respect to many of the affordances and alignment with policy, highlight certain aspects of the design and implementation processes which can relatively easily be addressed. They reveal the critical importance of sufficient scaffolding and support for students, along with feedback and communication of achievement to allow the opportunity for further reflection. Further research can usefully pursue similarly detailed accounts of lecturers' deployment and assessment of student activities in virtual worlds, in the pursuit of assessment best practice. 


\section{Acknowledgments}

The authors wish to express their gratitude to the Web 2.0 Assessment project team, and to the students who participated in the focus groups.

Support for this publication has been provided by the Australian Learning and Teaching Council Ltd, an initiative of the Australian Government Department of Education, Employment and Workplace Relations. The views expressed in this paper do not necessarily reflect the views of the Australian Learning and Teaching Council.

\section{References}

Beauvois, M. (1997). Write to speak: The effects of electronic communication on the oral achievement of fourth semester French students. In J. A. Muyskens (Ed), New ways of learning and teaching: Focus on technology and foreign language education. Heinle \& Heinle, Boston, MA, pp.93-116.

Chen, D. (2010). Enhancing the learning of Chinese with Second Life. Journal of Technology and Chinese Language Teaching, 1(1), 14-30. http:/ / www.tclt.us/ journal/2010v1n1/ chen.pdf

Cheng, L., Farnham, S. \& Stone, L. (2002). Lessons learned: Social interaction in virtual environments. In M. Tanabe, P. van den Besselaar \& T. Ishida (Eds), Digital cities. SpringerVerlag Berlin Heidelberg, pp. 203-218.

Cheung, H. J., Zhan, H. \& Tsai, A. (2010). Integrating Second Life into a Chinese teacher training program. Journal of Technology and Chinese Language Teaching, 1(1), 31-58. http: / / tclt.forlang.mtsu.edu/journal/2010v1n1/chengzhantsai.pdf

Dalgarno, B. \& Lee, M. J. W. (2010). What are the learning affordances of 3-D learning environments? British Journal of Educational Technology, 41(1), 10-32. http: / / dx.doi.org/10.1111/j.1467-8535.2009.01038.x

Dalgarno, B., Lee, M. J. W., Carlson, L., Gregory, S. \& Tynan, B. (2011). An Australian and New Zealand scoping study on the use of 3D immersive worlds in higher education. Australasian Journal of Educational Technology, 27(1), 1-15. http: / / ascilite.org.au/ ajet/ ajet27/ dalgarno.html

Deutschmann, M., Panichi, L. \& Molka-Danielsen, J. (2009). Designing oral participation in Second Life - a comparative study of two language proficiency courses. ReCall, 21(2), 206-226. http: / / dx.doi.org / 10.1017/ S0958344009000196

Diehl, W. C. \& Prins, E. (2011). Unintended outcomes in Second Life: Intercultural literacy and cultural identity in a virtual world. Language and Intercultural Communication, 8(2), 101-118. http: / / dx.doi.org/10.1080/14708470802139619

Elliott, B. (2008). Assessment 2.0: Modernising assessment in the age of Web 2.0. Glasgow: Scottish Qualifications Authority. [viewed 15 May 2011] http: / / www.scribd.com/ doc/461041/ Assessment-20

Ellis, R. (2008). The study of second language acquisition (2nd ed.). Oxford, UK: Oxford University Press.

Foster, P. \& Ohta, A. S. (2005). Negotiation for meaning and peer assistance in second language classrooms. Applied Linguistics, 26(3), 402-430. http: / / applij.oxfordjournals.org/ content/26/3/402.short

Gray, K., Thompson, C., Sheard, J., Clerehan, R. \& Hamilton, M. (2010) Students as Web 2.0 authors: implications for assessment design and practice in higher education. Australasian Journal of Educational Technology, 26(1), 105-122. http: / / ascilite.org.au/ajet/ajet26/gray.html 
Gray, K., Waycott, J., Clerehan, R., Hamilton, M., Richardson, M., Sheard, J. \& Thompson, C. (2010). Web 2.0 authoring tools in higher education learning and teaching: New directions for assessment and academic integrity: A framework for field-testing and refining good practice guidelines in pilot projects at Australian universities during Semester One 2010. [viewed 16 May 2011, verified 17 Aug 2011] http: / / web2assessmentroundtable.pbworks. com/f/ ALTC-ASW2A-Guidelines-draft-Feb2010.pdf

Harris, A. J. \& Rea, A. (2009). Web 2.0 and virtual world technologies: A growing impact on IS Education. Journal of Information Systems Education, 20(2), 137-144. [abstract only] http: / /jise.org/Issues/20/V20N2P137-abs.pdf

Henderson, M., Huang, H., Grant, S. \& Henderson, L. (2009). Language acquisition in Second Life: Improving self-efficacy beliefs. In Same places, different spaces. Proceedings ascilite Auckland 2009. http:/ / www.ascilite.org.au/conferences/auckland09/procs/henderson.pdf

Hudson, J. N. \& Bristow, D. R. (2006). Formative assessment can be fun as well as educational. Advances in Physiology Education, 30(1), 33-37. http: / / dx.doi.org/ 10.1152/ advan.00040.2005

Kirschner, P. A., Sweller, J. \& Clark, R. B. (2006). Why minimal guidance during instruction does not work: An analysis of the failure of constructivist, discovery, problem-based, experiential, and inquiry-based teaching. Educational Psychologist, 41(2), 75-86. [verified 17 Aug 2011] http: / / citeseerx.ist.psu.edu / viewdoc/ download?doi=10.1.1.169.8810\&rep=rep1\&type=pdf

Meyer, B. (2009). Designing serious games for foreign language education in a global perspective. Research, reflections and innovations in integrating ICT in education, Vol.1, pp. 715719. [verified 17 Aug 2011] http:/ / www.formatex.org/micte2009/book/715-719.pdf

Migdalek, J. (2002). Performing English: The classroom as rehearsal space. Prospect, 17(2), 53-61. [verified 17 Aug 2011] http:/ / www.ameprc.mq.edu.au/docs / prospect_journal/volume_17 _no_2/17_2_4_Migdalek.pdf

McLoughlin, C. \& Lee, M. J. W. (2007). Social software and participatory learning: Pedagogical choices with technology affordances in the Web 2.0 era. In ICT: Providing choices for learners and learning. Proceedings ascilite Singapore 2007.

http:/ / www.ascilite.org.au/conferences / singapore07/procs/mcloughlin.pdf

McLoughlin, C. \& Lee, M. J. W. (2011). Pedagogy 2.0: Critical challenges and responses to Web 2.0 and social software in tertiary teaching. In M. J. W. Lee \& C. McLoughlin (Eds), Web 2.0based E-learning: Applying social informatics for tertiary teaching. Hershey, PA: Information Science Reference, pp. 43-69.

O'Brien, M. G. \& Levy, R. M. (2008). Exploration through virtual reality: Encounters with the target culture. The Canadian Modern Language Review, 64(4), 663-691. http: / / dx.doi.org/10.3138/cmlr.64.4.663

Smart, J. (2010). How the television will be revolutionized: The exciting future of the $i P a d$, Internet TV, and Web 3.0. [viewed 15 May 2011] http:/ / www.accelerating.org/articles/televisionwillberevolutionized.html

Swain, M. (1995). Three functions or output in second learning. In G. Cook \& B. Seidlhofer (Eds), Principles and practice in applied linguistics. Oxford: Oxford University Press, pp. 125-144.

Taras, M. (2008). Summative and formative assessment: Perceptions and realities. Active Learning in Higher Education, 9(2), 172-192. http: / / dx.doi.org/10.1177/1469787408091655

Waycott, J., Gray, K., Clerehan, R., Hamilton, M., Richardson, J., Sheard, J., Thompson, C. (2010). Implications for academic integrity of using Web 2.0 for teaching, learning and assessment in higher education. International Journal for Educational Integrity, 6(2), 8-18. http: / / www.ojs.unisa.edu.au/index.php/IJEI/article/view / 699/527

Yin, R. K. (2003). Case study research: Design and methods. 3rd Ed., Thousand Oaks, CA: Sage. 


\section{Appendix: Desired learning outcomes for the assignment}

\section{Part A:}

a. Learn about a range of dishes common throughout mainland China (new cultural and linguistic knowledge)

b. Learn about a number of dishes suitable for individuals with specific dietary needs (new practical and linguistic knowledge)

c. Practise, consolidate and extend linguistic knowledge and communicative skills in relation to dishes, ingredients, numbers, quantity, currency and colours (consolidate classroom based learning and learn new terms and concepts)

d. Further familiarise students with the virtual environment of Chinese Island to facilitate subsequent lessons (new knowledge and skills)

\section{Part B:}

a. Learn about Chinese dumplings (new cultural and linguistic knowledge)

b. Practise reading task instructions in Chinese (consolidate classroom based learning)

c. Practise greeting someone in Chinese (consolidate classroom based learning)

d. Practise using Chinese to find someone (consolidate classroom based learning)

e. Practise following street directions in Chinese (consolidate classroom based learning)

f. Practise buying something in Chinese (consolidate classroom based learning)

Authors: Scott Grant, Faculty of Arts

Bldg 11, Clayton Campus

Monash University, VIC 3800

Email: scott.grant@monash.edu

Rosemary Clerehan, Faculty of Medicine, Nursing and Health Sciences

Bldg 15, Clayton Campus

Monash University, VIC 3800

Email: rosemary.clerehan@monash.edu

Please cite as: Grant, S. \& Clerehan, R. (2011). Finding the discipline: Assessing student activity in Second Life. In J. Waycott \& J. Sheard (Eds), Assessing students' Web 2.0 activities in higher education. Australasian Journal of Educational Technology, 27(Special issue, 5), 813-828. http:/ / www.ascilite.org.au/ajet/ ajet27/grant.html 